\title{
Organization Ethics in Healthcare
}

Bioethics, clinical ethics, and professional ethics are mature, welldeveloped fields of applied ethics that focus on medical research, patient autonomy and patient care, patienthealthcare professional relationships, and issues that arise in clinical and other medical settings. However, despite these developments, little attention has been paid to the organizational aspects of healthcare in these fields. This is surprising, because in the last 30 years healthcare has become more and more institutionalized in provider, management, and insurer organizations. Despite JCAHO's preoccupation with organizational ethics during the last decade, the philosophical underpinnings of their requirements have been less explored in the literature. Clinical ethics remains preoccupied with clinical patient care and professional ethics with individual professional guidelines; even the American College of Healthcare Executives focuses primarily on healthcare managers, not on healthcare organizations.

It would appear that the topic of healthcare organizations is an ideal subject for business ethics. Yet interestingly, business ethics, whose subject matter is in large part corporations, has not taken the lead in thinking about healthcare organizations.

Because of the paucity of literature and research in the field of organization ethics for healthcare, the University of Virginia's Center for Biomedical
Ethics in conjunction with the Olsson Center for Applied Ethics at the Darden Graduate School of Business Administration organized a conference in September 1998 specifically to address ethical issues in healthcare organizations, where the primary emphasis was on the organizational dimensions of these issues. The papers in this collection represent some of the best thinking at that conference.

The first paper, by Linda Emanuel, introduces the notion of organization ethics. She argues that organizations and structures, like individuals, have ethical attributes and can be held morally accountable. Patricia Werhane contends that business ethics, and in particular, stakeholder theory, has a great deal to contribute to the thinking about organization ethics in healthcare. Further papers by John Paris, George Agich and Heidi Forster, and Rosamond Rhodes and James Strain focus on particular aspects of organization ethics. John Paris challenges us to rethink our critiques of costcontrol practices in managed care, particularly in light of serving patient populations rather than singling out individual patient optimum benefits. George Agich reminds us of the central role of managing healthcare and thus the responsibilities of managers as well as healthcare professionals to the mission of healthcare organizations. Rosamond Rhodes shows how trust is a central moral category whether one is dealing 
with particular patient-physician relationships, patient-hospital relationships, or, on an organizational level, as the moral basis for medical institutions.

Bethany Spielman's essay deals with an external but critical stakeholder for healthcare organizations: the law. Spielman elaborates on the complex relationships between regulation, healthcare organizations, and organization ethics programs, and argues that these relationships cannot be ignored in thinking about the multiple dimensions of organization ethics.

The last essay in this collection points to a dark side of present healthcare. In the era of growth and consolidation of healthcare organizations, rural health and rural healthcare suffers even more than it has in past decades. In our pre- occupation with the expansion of large healthcare organizations, rural healthcare centers cannot compete, as Ann Cook aptly demonstrates. They suffer from lack of funds, which translates into an inability to serve their sparsely distributed populations or to offer technological advances required for adequate care.

Together these papers help to introduce the notion of organizational ethics in healthcare, and two papers focus on particularly troubling issues: regulation and rural healthcare. They are meant to invite readers to think deeply about the ethics of healthcare organizations and to develop further analyses of what should be central issues for healthcare in the next century. 